\title{
SalaBil: plataforma de ensino bilíngue
}

Cristina Almeida da Silva - IFRS - crisalm.silva@gmail.com Márcia

Häfele Islabão Franco - IFRS - marcia.franco@ poa.ifrs.edu.br Fábio

Yoshimitsu Okuyama - IFRS - fabio.okuyama@ poa.ifrs.edu.br

Resumo: Com o intuito de auxiliar o professor na criação de materiais didáticos para uso com alunos surdos, foi criada a plataforma educacional intitulada SalaBil. A mesma é composta por uma área onde o professor planeja e monta suas aulas e uma área onde o aluno realiza as atividades propostas. Essas podem ser: textos, imagens, jogos de memória, jogos de ligar e questionários. Os diferenciais da plataforma são o dicionário, o compartilhamento e a reutilização de materiais didáticos. Foi feita uma parceria com uma escola especial de surdos em Porto Alegre, que auxiliou desde o planejamento das funcionalidades da plataforma até a implantação. A metodologia utilizada foi a pesquisa aplicada. Foram realizadas capacitações no SalaBil onde os professores criaram materiais e aplicaram com seus alunos.

Palavras-chave: Libras, educação bilíngue de surdos, acessibilidade, tecnologias digitais, letramento digital.

\section{SalaBil: bilingual teaching platform}

Abstract: In order to assist the teacher in the creation of didactic material for use with deaf students, the educational platform entitled SalaBil was created. It is composed of an area where the teacher plans and create his lessons and an area where the student performs the proposed activities, which can be: texts, images, memory games, connect the dots games and quizzes. SalaBil differentials include the dictionary and possibility of sharing and reuse of teaching materials. For the creation of the platform, a partnership with a special school of deaf people of Porto Alegre was made, them helped from the planning of the functionalities until its implementation. The methodology used is the applied research. Training was carried out on SalaBil from which teachers created materials and applied with their students.

Keywords: Libras, bilingual education of deaf people, acessibility, digital technologies, digital literacy.

\section{Introdução}

A Língua Brasileira de Sinais (Libras) é a língua materna usada pela maioria dos surdos no Brasil, e é reconhecida como meio legal de comunicação e expressão desde a promulgação da Lei $\mathrm{n}^{\circ} 10.436$, de 24 de abril de 2002, que dispõe que a língua portuguesa não poderá ser substituída pela Libras na modalidade escrita (BRASIL, 2002).

Ela foi regulamentada pelo Decreto $n^{\circ} 5.626$, de 22 de dezembro de 2005 e desde então é reconhecida como língua oficial no Brasil. Esse decreto dispõe sobre a inclusão de Libras como disciplina curricular e sobre a formação do professor e do instrutor de Libras (BRASIL, 2005). A Lei Brasileira de Inclusão da Pessoa com Deficiência (Lei no 13.146, de 6 de julho de 2015) prevê a oferta de educação bilíngue, onde Libras é a primeira língua utilizada pelos surdos, também conhecida como L1 e o português a segunda na modalidade escrita, também conhecida como L2 (BRASIL, 2015). Essa é a situação atual da legislação brasileira em prol da comunidade surda.

A partir de entrevistas realizadas com especialistas da área da surdez, ficou evidente a existência de uma demanda por um ambiente onde seja possível dicionarizar os verbetes de Libras, associando os mesmos a imagens de sinais, de vídeos e de imagens 
diversas que possam ser utilizadas em sala de aula. Além da dicionarização, a recuperação rápida e fácil da mesma, aliada a uma forma de transformar esses materiais em jogos e atividades. Esse é o objetivo do trabalho aqui apresentado, desenvolver uma plataforma para auxiliar os professores na criação de materiais didáticos para o ensino de surdos.

Para o desenvolvimento da plataforma foi efetuada uma parceria com uma escola especial para surdos de Porto Alegre, que participou do projeto desde sua concepção até a sua implantação. Essa escola é bilíngue e ensina Libras, escrita de língua de sinais (ELS) e o português escrito. A plataforma desenvolvida pode ser utilizada por outras escolas, e todas que tiverem interesse poderão compartilhar seus dicionários. Para fins dessa pesquisa, somente os dados produzidos pela escola parceira foram objeto de análise.

Na próxima seção serão abordados alguns referenciais teóricos necessários para embasar a necessidade de uma plataforma que dê suporte a um ensino bilíngue.

\section{Referencial Teórico}

Importante destacar que a pesquisa prioriza o ensino bilíngue, tanto para atender a proposta pedagógica da escola parceira, como também em decorrência do resultado da pesquisa bibliográfica realizada. Considerando que o bilinguismo possibilita que o indivíduo surdo se expresse na sua língua materna, respeitando o seu processo de apreensão do mundo que é visual (QUADROS; SCHMIEDT, 2006).

A proposta bilíngue que compreende a competência e o desempenho em duas línguas é atualmente a mais aceita pela comunidade surda e está garantida no Decreto $\mathrm{n}^{\mathrm{o}}$ 5.626, de 22 de dezembro de 2005 (BRASIL, 2005). Essa modalidade considera a língua de sinais como a língua materna para o surdo, devido à sua habilidade visual, é a sua primeira língua.

Conforme Skliar (2013), 95\% das crianças surdas têm pais ouvintes e devido ao desconhecimento por parte dos pais da língua de sinais, elas são alfabetizadas em Libras tardiamente, ou seja, a escola acaba assumindo o papel de ensinar Libras às crianças e suas famílias. Enquanto a criança não adquire sua língua materna ela utiliza sinais caseiros com seus pais e familiares (SKLIAR, 2013).

Skliar (2013) diz ainda que a criança deveria adquirir a língua de sinais até os três anos de idade para obter fluência (SKLIAR, 2013). Segundo Cruz (2016) "qualquer criança adquire a linguagem quando dispõe das oportunidades naturais de aquisição. No caso das crianças surdas filhas de pais surdos esse processo acontece naturalmente na língua de sinais". Ela destaca que as crianças surdas estão em iguais condições de desenvolvimento das crianças ouvintes (CRUZ, 2016, p.15).

Algumas escolas especiais de surdos utilizam a ELS, também conhecida como SignWriting (SW), além do português escrito. Segundo Oliveira e Stumpf (2013) a ELS "é um sistema visual de registro das línguas de sinais. Os símbolos utilizados nesta escrita buscam expressar os movimentos, as formas das mãos, as expressões não-manuais e os pontos de articulação" (OLIVEIRA; STUMPF, 2013, p. 225).

Esse breve resumo da pesquisa bibliográfica realizada teve por objetivo explicar a importância do bilinguismo para a criança surda e a importância de que ela domine tanto a Libras como o Português.

\section{Trabalhos Relacionados}

Fernandes e Rodrigues (2016) apresentam um software para auxiliar deficientes auditivos na aprendizagem da Língua Portuguesa. A proposta é que a criança assista a um vídeo em Libras e em seguida complete as frases apresentadas preenchendo as lacunas. No primeiro nível é necessário completar uma palavra, chegando até quatro palavras no último nível, aumentando gradativamente a complexidade. A ferramenta disponibiliza, ainda, vídeos 
com orientações sobre como realizar as tarefas, vídeos motivacionais ou ainda, vídeos para complementar a matéria. Há ainda um ambiente onde o professor tem algumas opções de administração da ferramenta, como: parametrizar as frases apresentadas, inserir vídeos e acompanhar o número de acertos e de erros de cada aluno (FERNANDES; RODRIGUES, 2016).

Carvalho e Ferreira (2011) propõem um jogo para auxiliar no desenvolvimento do vocabulário da língua portuguesa em crianças surdas. Nele estão previstos dois tipos de usuários: um administrador responsável por inserir palavras, organizá-las em categorias e subcategorias e definir o número de atividades que o aluno deve realizar (CARVALHO; FERREIRA, 2011).

O trabalho de Brito e Ferreira (2015) prevê a construção de uma ferramenta que favorece "o aprendizado do aluno surdo, auxiliando no processo de interpretação e reconhecimento da escrita em língua portuguesa, visando a aquisição e reforço do aprendizado e compreensão do significado do vocabulário" (BRITO; FERREIRA, 2015, p. 2). A ferramenta inicia com uma atividade para relacionar um adjetivo com seu oposto, na sequência aparecem cenários com os mesmos adjetivos para fixação dos conceitos com o intuito de verificar o aprendizado ocorrido na primeira fase. Em seguida, a escrita do adjetivo é apresentada em língua portuguesa e no alfabeto manual junto com um cenário que ilustra os conceitos que estão sendo estudados e ainda, com um vídeo dessas palavras (BRITO; FERREIRA, 2015).

Quixaba e Junior (2016) relatam o processo de desenvolvimento de um protótipo de "um recurso didático-pedagógico para potencializar o ensino e aprendizagem de Libras a toda a comunidade educacional", o qual eles definem como sendo um objeto de aprendizagem. Ele é composto por textos, vídeos e imagens. Pode ser reusado em contextos diferentes e em mais de uma disciplina (QUIXABA; JUNIOR, 2016, p.2).

Importante destacar que durante essa pesquisa, além dos trabalhos descritos nessa seção, foram encontrados outros trabalhos relacionados ao tema proposto. Porém, devido ao espaço destinado a essa seção, foram apresentados os trabalhos que apresentam o maior número de características semelhantes a plataforma SalaBil, que é o produto gerado nessa pesquisa e, que de alguma forma tratam o bilinguismo (Português-Libras).

Nenhum dos trabalhos pesquisados dispõem da ferramenta dicionário e da funcionalidade de compartilhamento da mesma entre os professores, com o intuito de disseminar o conhecimento e unificar os sinais utilizados. Além disso, outro diferencial da plataforma SalaBil é a possibilidade de criação das aulas com diversas atividades e o compartilhamento das mesmas no ambiente. Em nenhum os trabalhos pesquisados há muitas opções de vocabulário, além de não terem possibilidade de expansão, característica está também presente da plataforma proposta.

A próxima seção irá explanar como foi o desenvolvimento desse projeto que deu origem a plataforma de ensino SalaBil.

\section{Contexto, Materiais e Métodos}

Com o intuito de averiguar como as políticas públicas refletem na organização das escolas e entender as necessidades e as dificuldades encontradas no processo de ensino de crianças surdas, foram realizadas entrevistas com professores surdos e ouvintes, fonoaudiólogos e intérpretes de Libras. Como resultado dessa pesquisa inicial foi identificada a dificuldade para obter materiais de qualidade para ministrar as aulas. Também, não existe um local para armazenamento e catalogação dos materiais, nem a cultura do compartilhamento. Na internet também é difícil encontrar materiais voltados à educação de surdos, havendo quase sempre necessidade de adaptação.

As considerações acima expostas, aliadas ao referencial teórico discutido na seção 
anterior ressaltam a necessidade de apresentar, o mais cedo possível a Libras para a criança surda, e a importância do ensino bilíngue. Esse foi o contexto que evidenciou a necessidade de gerar uma plataforma foi decidido e em função disso seria realizada uma pesquisa aplicada.

O desenvolvimento da plataforma SalaBil foi realizado em parceria com uma escola especial para surdos de Porto Alegre, que atende crianças da educação infantil até o nono ano. Participaram ativamente do projeto 16 professores, além de contar com a colaboração da coordenadora pedagógica e do apoio da diretoria. Importante destacar que esse projeto tem aprovação do Comitê de Ética em Pesquisa envolvendo seres humanos do Instituto Federal de Educação, Ciência e Tecnologia do Rio do Sul, sob comprovante número 049444/2017.

Os dezesseis professores colaboradores do projeto são proficientes na língua de sinais e atualmente todos estão aprendendo e já utilizando a ELS em sala de aula, desses três são surdos. Há nesse grupo ao menos um professor de cada turma da escola, pois foi definido pela coordenadora pedagógica que a plataforma será utilizada por todos os professores e com todos os alunos.

A primeira etapa realizada foi um levantamento bibliográfico sobre a educação de surdos mediada pela tecnologia da informação. Além de temas relacionados a surdez, foram efetuadas pesquisas sobre métodos pedagógicos de ensino de L1 e L2 e assuntos relativos a tecnologias acessíveis.

A segunda etapa foi a análise dos requisitos que consistiu em um levantamento de informações necessárias à construção da plataforma proposta, e teve como resultado uma lista de funcionalidades. Para isso, foram realizadas reuniões não estruturadas com a coordenadora pedagógica nas quais ela explicou a metodologia pedagógica da escola, o tipo de trabalho conduzido pelos professores e enfatizou a necessidade de compartilhamento de materiais entre os professores e do desejo de criar um dicionário que pudesse ser compartilhado entre os professores, com o intuito de disseminar o conhecimento e unificar os sinais utilizados.

Nesta etapa foi aplicado um questionário estruturado com os professores participantes. O Quadro 1 apresenta questões referente a obtenção, armazenamento e compartilhamento dos materiais, bem como, as respostas fornecidas pelos participantes.

\begin{tabular}{|c|c|}
\hline Perguntas & Respostas \\
\hline Você cria seus materiais? & $36 \%$ responderam sempre, $36 \%$ às vezes e $27 \%$ não responderam. \\
\hline $\begin{array}{l}\text { Você obtém material com seus } \\
\text { colegas? }\end{array}$ & $9 \%$ responderam sempre, $55 \%$ às vezes e $36 \%$ não responderam. \\
\hline Você pesquisa materiais na internet? & $36 \%$ responderam sempre, $27 \%$ às vezes e $36 \%$ não responderam. \\
\hline Você busca em livros ou apostilas? & $\begin{array}{l}45 \% \text { responderam sempre, } 18 \% \text { responderam às vezes, } 9 \% \\
\text { responderam nunca e } 27 \% \text { não responderam. }\end{array}$ \\
\hline Você confecciona seus materiais? & $9 \%$ respondeu que sempre e $91 \%$ não responderam. \\
\hline $\begin{array}{l}\text { Como você armazena seus materiais } \\
\text { (imagens, vídeos, textos, atividades, } \\
\text { aulas, outros). Essa resposta permitia } \\
\text { múltiplas respostas. }\end{array}$ & $\begin{array}{l}27 \% \text { armazenam em sua pasta (material impresso); } 9 \% \text { em um } \\
\text { diretório compartilhado na escola; } 45 \% \text { em um diretório em seu } \\
\text { computador; } 45 \% \text { em uma pendrive. }\end{array}$ \\
\hline $\begin{array}{l}\text { Com que frequência você efetua seus } \\
\text { backups/cópias? }\end{array}$ & $\begin{array}{l}9 \% \text { nunca; } 9 \% \text { diariamente; } 9 \% \\
\text { eventualmente; } 55 \% \text { não responderam. }\end{array}$ \\
\hline $\begin{array}{l}\text { Você costuma compartilhar os } \\
\text { materiais que você cria (textos, } \\
\text { imagens, vídeos, atividades, aulas)? } \\
\text { Com quem? }\end{array}$ & $\begin{array}{l}\text { 9\% não compartilha; } 36 \% \text { compartilha com alguns colegas da } \\
\text { escola; } 9 \% \text { compartilha com todos os colegas da escola; } 9 \% \\
\text { compartilha com alguns colegas mesmo que fora da escola; } 9 \% \\
\text { compartilha com alguns colegas mesmo que fora da escola; } 36 \% \\
\text { não responderam. }\end{array}$ \\
\hline
\end{tabular}

Quadro 1 - Questionário aplicado aos professores participantes da pesquisa 
Analisando o quadro percebe-se que não existe o hábito do compartilhamento de materiais entre os professores e, também há uma fragilidade muito grande quanto aos backups realizados.

A partir dessa pesquisa inicial o escopo foi definido e foi iniciada a prototipação da plataforma. Para isso, foi utilizada a ferramenta Moqups $^{1}$, que proporcionou agilidade, permitiu correções com facilidade e, também, possibilitou a programação da navegação entre as telas, simulando o comportamento do sistema com um alto nível de detalhamento. De acordo com Sharp, Rogers e Preece (2013), "Um protótipo é uma manifestação de um design que permite às partes interessadas interagir com ele e explorar sua adequação" (ROGERS; SHARP; PREECE, 2013, p. 390).

Para ter um feedback da prototipação, foram realizados dois tipos de validação, o primeiro foi o teste manual, ou teste de baixa fidelidade, as telas foram impressas e os usuários tentaram compreender como o sistema iria se comportar. No segundo, no teste de alta fidelidade, os usuários utilizaram a versão no computador e verificaram se o fluxo sugerido estava adequado.

Para o teste manual uma professora, que não conhecia o projeto, foi convidada para fazer o papel de usuária. Além dela, havia uma pessoa representando o papel de entrevistador, e uma terceira pessoa fez o papel de computador, ou seja, mostrava as telas de acordo com as opções da usuária. Após uma breve explicação das regras, o teste começou com o computador apresentando a tela inicial e o entrevistador perguntou à usuária o que ela achava que era aquela tela e que ações ela poderia efetuar. Conforme as ações que ela efetuava, o computador apresentava a tela correspondente, por exemplo, na primeira tela foi selecionada a opção 'Cadastrar-se' e o computador apresentou a tela de Cadastro do Professor. E assim, foi feito com todas as telas do protótipo.

Deste teste foi possível identificar que haviam pontos confusos e que faltavam algumas informações nas telas. Dentre outras sugestões, a professora comentou que na tela onde o professor configura o jogo de memória, seria melhor utilizar 'número de pares de cartas' ao invés de 'número de cartas'. Todas as observações foram anotadas, e a partir do relatório gerado foram efetuadas alterações no protótipo.

Para possibilitar o teste do protótipo de alta fidelidade foram inseridas interações entre as telas, dando um dinamismo similar ao do produto pronto. Conforme Sharp, Rogers e Preece (2013), ele é útil para testar dificuldades técnicas e vender ideias (ROGERS; SHARP; PREECE, 2013).

Esse protótipo foi apresentado para a coordenadora pedagógica e para a professora de português da escola parceira do projeto. Foram revisadas todas as telas, bem como a navegação entre elas e a clareza de cada ação. Elas relataram que as telas eram intuitivas e confirmaram que os termos utilizados estavam corretos. Inclusive foi questionado se na tela de definição do jogo da memória seria melhor utilizar 'número de cartas' ou 'número de pares de cartas' e elas confirmaram o uso da primeira opção.

A professora de português ressaltou a importância da ferramenta 'dicionário' e sugeriu que o questionário permitisse a inclusão de questões subjetivas que serão corrigidas posteriormente pelos professores, segundo ela, isso dará mais flexibilidade e deixará o produto mais completo.

A coordenadora pedagógica comentou que o projeto da forma como está, não precisa se ater apenas aos anos iniciais como inicialmente idealizado, mas que o mesmo pode ser utilizado por professores de outras matérias, inclusive dos anos finais.

${ }^{1}$ Disponível em <https://moqups.com>. Acesso em mar. 2017. 
Com a validação do protótipo, foi encerrada a fase de análise com requisitos consistentes para iniciar a fase de desenvolvimento da plataforma. A próxima seção apresenta a plataforma SalaBil.

\section{Plataforma SalaBil}

A plataforma foi desenvolvida com dois ambientes distintos: um portal do professor e um portal do aluno. Ambos rodam na plataforma web e mobile. No portal do professor ele irá construir um dicionário de acordo com as suas necessidades para uso em sala de aula, e cada verbete inserido poderá ser utilizado para criar atividades que serão executadas pelos alunos no computador da sala de aula ou de sua casa, uma vez que as atividades estarão todas disponíveis na internet. O dicionário ficará disponível para uso de toda comunidade da escola, sendo possível ainda, que uma escola compartilhe seus materiais com outra.

O portal do professor foi desenvolvido primeiro, pois não seria possível validar o portal do aluno sem o professor ter feito todas suas configurações. Esse módulo é composto pelos cadastros de escola, professor, turmas, aluno, verbetes, aulas e atividades.

Todas as telas de cadastro são compostas por uma tela de pesquisa, como a que é apresentada na Figura 1 que dá acesso a uma grade com o resultado da pesquisa, a partir da qual é possível consultar, alterar ou excluir um registro.

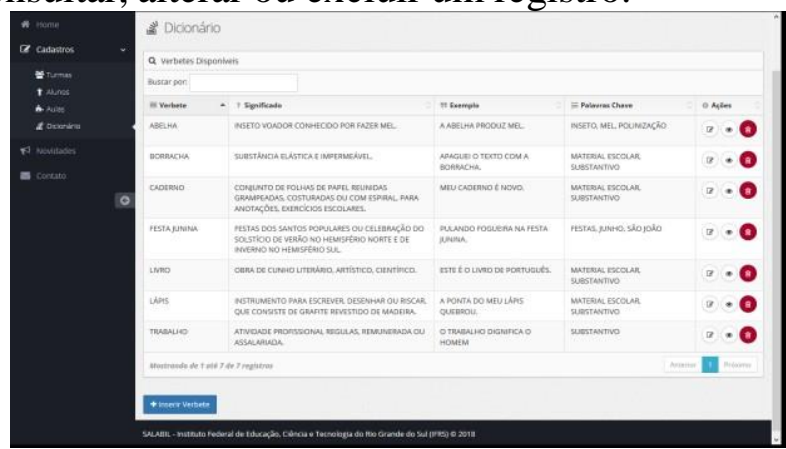

Figura 1 - Tela de pesquisa do dicionário. Plataforma SalaBil, www.salabil.com.br.

O dicionário é a base da criação de atividades na aplicação e deverá ser alimentado constantemente pelos professores. Todos os verbetes inseridos no dicionário ficam disponíveis para consulta e uso de todos. A Figura 2, apresenta a consulta do verbete 'abelha'. Assim, por exemplo, um professor pode adicionar uma nova imagem, um vídeo, uma datilologia, uma ELS (Figura 3) ou palavra-chave a um verbete que tenha sido criado por outro, sem que isso afete o trabalho já realizado pelo primeiro.

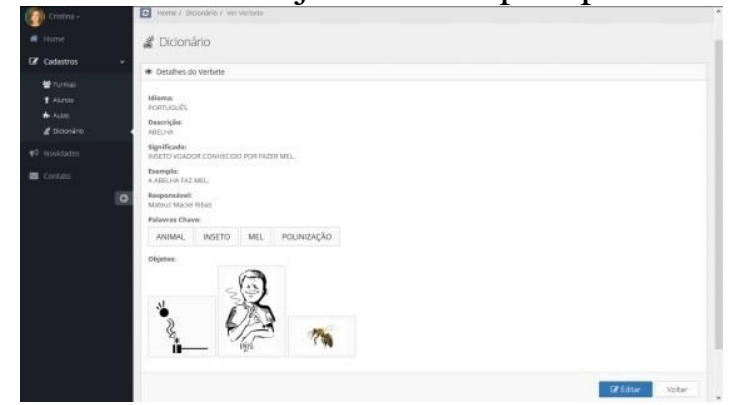

Figura 2 - Tela de consulta de um verbete. Plataforma SalaBil, www.salabil.com.br

Também é possível efetuar a pesquisa pelo nome do verbete ou por uma palavrachave, por isso a sugestão é que ao incluir um verbete sejam associadas o máximo de palavras-chave possíveis, pensando em como essa palavra pode vir a ser pesquisada.

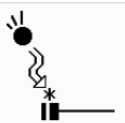

Figura 3 - Imagem da ELS de abelha. Plataforma Salabil, www.salabil.com.br. 
Para a configuração das aulas e suas atividades o professor deve efetuar o cadastro de uma aula e indicar a turma e o dia em que a aula será ministrada, bem como o objetivo, o plano de ensino, as competências e habilidades que serão trabalhadas. Em seguida, o professor irá inserir quantas atividades desejar na aula, iniciando pela definição do tipo de atividade que poderá ser um ou mais textos com ou sem imagens, jogos de memória, jogos de ligar ou questionários. A ideia é que o professor possa utilizar esses quatro tipos de atividades para criar aulas de diferentes tipos de complexidade. Importante destacar que essa funcionalidade não está presente nos trabalhos relacionados pesquisados e foi solicitada pelos professores da escola parceira dessa pesquisa.

A atividade texto pode ser composta de textos e imagens como apresentado na Figura 4. Assim o professor pode criar nessa atividade diferentes configurações, como: um ou dois textos lado a lado, um texto e uma imagem, uma ou duas imagens. A Figura 4, mostra como o professor insere uma atividade com texto e imagem, no caso apresentado, a opção foi um texto em português e uma imagem que foi selecionada do banco de imagens do professor.

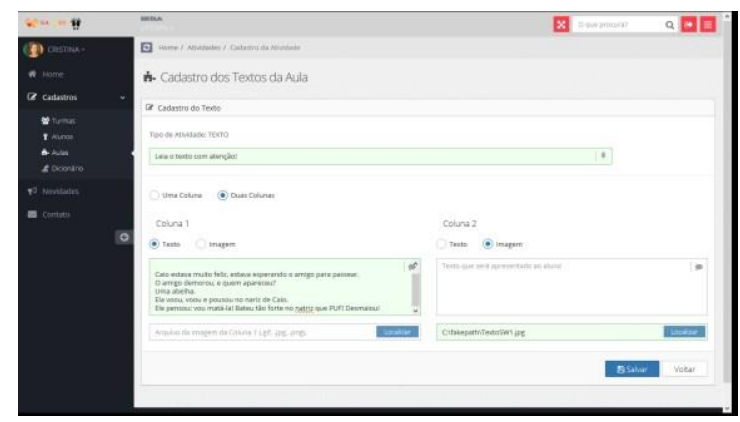

Figura 4 - Tela de inclusão de uma atividade de texto. Plataforma SalaBil, www.salabil.com.br.

As atividades de jogo de memória e do jogo de ligar têm uma dinâmica similar. O professor irá selecionar as imagens do dicionário, aqui a complexidade será definida conforme as imagens selecionadas. Podem ser selecionadas duas imagens iguais como em um jogo de memória convencional, ou podem ser imagens diferentes de um mesmo verbete, por exemplo um desenho e o seu sinal, ou o sinal e a representação em datilologia, ou a escrita em português e a ELS entre outras combinações possíveis.

O questionário permite parametrizações específicas para a pergunta e para a resposta, porém em ambas, o professor poderá optar pelo uso do português, da ELS, de uma imagem ou ainda poderá utilizar um vídeo. A resposta pode ser subjetiva, objetiva ou uma imagem. Se for subjetiva o aluno deverá escrever a resposta seguindo a orientação do professor, pode responder em português, em ELS, com uma imagem ou ainda um vídeo, após inserir a resposta ele deve salvar para o professor corrigir. Se a reposta for objetiva, o professor irá escrever as possíveis respostas e irá indicar qual ou quais são as corretas para que seja possível a correção automática.

Para evitar que o aluno tenha dúvidas o professor poderá criar um vídeo e anexar em cada atividade para que o aluno assista as instruções de como realizar cada atividade.

\section{EXPERIMENTOS REALIZADOS}

Após o desenvolvimento da plataforma finalizado, foram realizados três experimentos com os professores participantes da pesquisa, sendo todos realizados na escola parceira desse projeto.

No primeiro experimento, realizado em março de 2018, durante a reunião pedagógica, foi feita uma apresentação da plataforma para todos os professores da escola, com duração de uma hora, com o intuito de convidá-los a usá-la com suas turmas. Eles 
tinham várias dúvidas, por exemplo: 1) Poderiam usar a ELS?, 2) Quantas imagens poderiam inserir?, 3) Poderiam inserir vídeos?, 4) Quais os formatos permitidos?, 5) Qual o tamanho permitido para o vídeo?.

Os professores ficaram mais tranquilos quando receberam resposta positiva para essas questões e ainda, que teriam os formatos mais comuns disponíveis para upload. E para não termos limitação no tamanho dos vídeos, foi decidido que os mesmos serão postados no youtube, em um canal privado, e o link será copiado para a atividade.

Ainda nesse primeiro experimento, foi proposto que eles batizassem a plataforma e após algumas sugestões todos concordaram com o nome SalaBil, que é o acrônimo de 'sala de aula bilíngue'. No mesmo momento já criaram um sinal e um dos professores gentilmente disponibilizou o mesmo na ELS conforme apresentado na Figura 5, que é a representação das mãos espalmadas com as palmas para frente, dedos para cima, batendo os polegares duas vezes. Esse sinal foi adicionado na barra de identificação da plataforma.

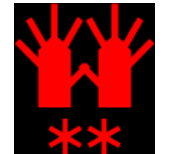

Figura 5 - Sinal da Plataforma SalaBil. www.salabil.com.br.

O segundo experimento ocorreu em junho de 2018, nesse momento foi realizada uma capacitação de uma hora, para que os professores pudessem conhecer a plataforma. Os professores gostaram muito da ideia de deixar o dicionário disponível para todos na escola e já combinaram que os professores das disciplinas especialistas, como: português, matemática, ciências, entre outros, serão responsáveis por adicionar os termos técnicos de suas disciplinas no dicionário.

Ficou claro nesse experimento que há níveis diferentes de conhecimento de tecnologia entre os professores, alguns entenderam e passaram por todas as funcionalidades em minutos, enquanto outros não conseguiram passar por todas. $\mathrm{O}$ que confirma o pressuposto de que a plataforma irá auxiliar no letramento digital dos professores e não apenas dos alunos.

No terceiro experimento em agosto de 2018, os professores tinham que inserir suas turmas e suas primeiras aulas. Porém, alguns minutos após o trabalho iniciar, houve um problema elétrico e a sala de informática não pode ser utilizada. Para aproveitar o encontro, todos foram para a sala dos professores e um deles ficou responsável por utilizar a plataforma enquanto sua tela era projetada na parede por um retroprojetor.

Assim, os professores puderam tirar dúvidas quanto as possibilidades de uso da plataforma. Tiveram oportunidade de estabelecer padrões de nomenclaturas de usuários e de turmas, uso de maiúsculas e minúsculas e planejamento de palavras-chave. Definiram como será inserida a ELS e os vídeos. Também solicitaram que fosse possível incluir as fotos dos alunos. No final da manhã haviam sido incluídas todas as turmas e todos os alunos da escola, bem como, vários verbetes, com imagens, ELS e vídeos. Além disso, foi possível incluir duas aulas com atividades.

A partir dessa capacitação os professores passaram a inserir atividades na plataforma sem a necessidade de acompanhamento da pesquisadora.

\section{Resultados e Discussão}

Foi efetuada uma análise da qualidade da plataforma enquanto recurso digital, para isso, foram utilizados os critérios elencados por Reis e Gomes (2014), conforme apresentado no Quadro 2, que apresenta a avaliação de três aspectos: linguístico, pedagógico e tecnológico. Como a plataforma é totalmente parametrizável os aspectos linguísticos e pedagógicos serão definidos pelo professor que poderá adaptar aos seus alunos de acordo 
com a faixa etária, nível escolar, e ainda, de acordo com a abordagem pedagógica adotada pela escola. Cabe então, somente a avaliação do aspecto tecnológico.

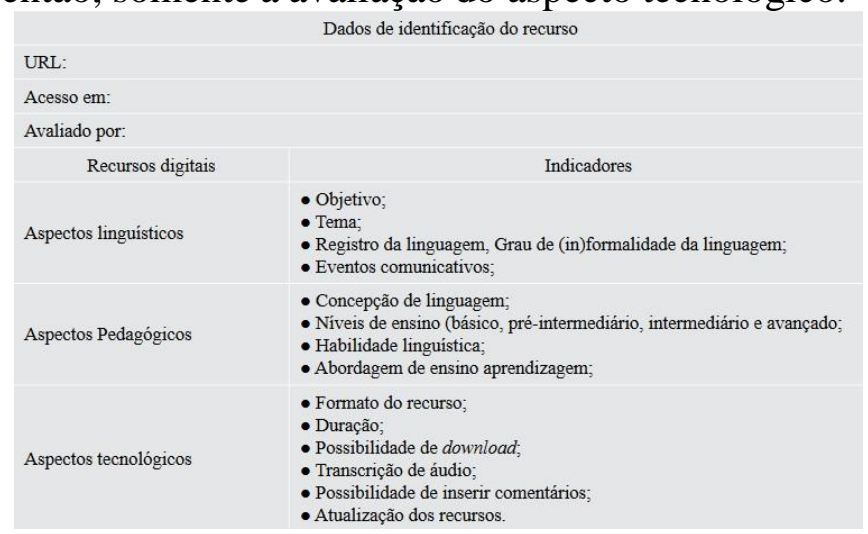

Quadro 2 - Critérios de avaliação dos recursos digitais. Reis e Gomes (2014).

Quanto ao formato do recurso: a plataforma está disponível on-line e pode ser acessada via web, tanto por um computador, um tablet ou um smartphone. Pode ser um limitador caso não haja um bom sinal de internet.

Quanto à duração, o professor irá decidir o número de atividades que ele irá disponibilizar e o tamanho de cada uma. Também é possível realizar download. Quanto à transcrição de áudio, não se aplica.

Quanto à possibilidade de inserir comentários, existe inclusive a possibilidade de o professor inserir vídeos explicativos para cada aula e para cada atividade. Quanto à atualização dos recursos, como a ferramenta é on-line, novas versões com correções e novas funcionalidades são imperceptíveis. Também foi criado um ícone de novidades, onde todas as alterações são listadas para conhecimento dos professores.

Os professores destacam as vantagens do uso do dicionário e o valor desse compartilhamento entre eles, e já vislumbraram que com a adesão de outras escolas esse dicionário pode se tornar uma ferramenta de consulta para a comunidade surda.

\section{CONCLUSÕES}

O objetivo desse projeto é auxiliar o professor no processo de ensino de surdos, a partir de um ambiente no qual o professor possa planejar, criar, compartilhar e reutilizar os conteúdos de aprendizagem.

A plataforma ainda não foi utilizada pelos alunos, pois os professores ainda estão alimentando a base com verbetes. No depoimento deles foi relatado que perceberam que esse é um processo trabalhoso no início, porém, entenderam que quando o dicionário estiver com verbetes variados, para a criação de novas aulas, o professor poderá se preocupar apenas com o conteúdo a ser ministrado e não onde achar objetos para utilizar.

Confirmando a análise da qualidade efetuada na plataforma enquanto recurso digital. A opção de tornar a plataforma totalmente parametrizável era justamente para permitir que os professores tivessem a liberdade quanto aos aspectos linguísticos e pedagógicos. Pois são eles que conhecem seus alunos e poderão elaborar sua aula de acordo as habilidades e competências de cada turma, respeitando a abordagem pedagógica adotada pela escola.

Para validar os experimentos realizados será aplicado um questionário estruturado com os professores, mas eles precisam usar por um tempo e criar algumas aulas antes dessa aplicação. A partir desse questionário pretende-se verificar questões de usabilidade, satisfação, facilidade de uso e de aprendizagem da plataforma pelo professor. E principalmente, validar se a plataforma foi um diferencial na qualidade do material 
gerado, no tempo gasto pelo professor no preparo da aula, e ainda, se houve e qual foi o impacto causado pelo compartilhamento de materiais?

A ideia dos professores é utilizar as atividades elaboradas na plataforma para consolidar o conteúdo trabalhado com os alunos, durante as aulas na sala de informática.

Com essa plataforma consolidada o dicionário criado pelos professores poderá ser tornado público e utilizado por outras escolas, esse compartilhamento de materiais ajuda a disseminar o conhecimento da Libras, da ELS, dos sinais já criados e utilizados em cada escola. Os professores dessa escola já perceberam o valor desse compartilhamento entre eles e já vislumbraram que com a adesão de outras escolas esse dicionário pode se tornar em uma ferramenta muito valiosa para a comunidade surda.

\section{REFERÊNCIAS BIBLIOGRÁFICAS}

BRASIL. Presidência da República. Decreto $n^{\circ}$ 5.626, de 22 de dezembro de 2005.

BRASIL. Presidência da República. Lei no 10.436, de 24 de abril de 2002.

BRASIL. Presidência da República. Lei no 13.146, de 6 de julho de 2015.

BRITO, Bruno Pereira; FERREIRA, Benedito de Jesus. Proposta de uma ferramenta de reforço de vocabulário na educação de surdos. RENOTE, 2015. v. 13, n. 1.

CARVALHO, N. A.; FERREIRA, B. J. Projeto e implementação de uma ferramenta voltada ao desenvolvimento do vocabulário em língua portuguesa de crianças surdas. RENOTE, 2011. v. 9, n. 3.

CRUZ, C. R. Consciência fonológica na língua de sinais brasileira (libras) em crianças e adolescentes surdos com início da aquisição da primeira língua (libras) precoce ou tardio. Porto Alegre: Universidade Federal do Rio Grande do Sul UFRGS, 2016.

FERNANDES, J. C. L.; RODRIGUES, S. C. M. Ambiente virtual de aprendizagem na educação de deficientes auditivos. RIT - Revista Inovação Tecnológica, 2016. v. 6, n. 2, p. 80-91.

OLIVEIRA, J. S.; STUMPF, M. R. Desenvolvimento de glossário de Sinais Acadêmicos em ambiente virtual de aprendizagem do curso Letras-Libras. Informática na Educação: teoria \& prática. Porto Alegre, 2013, v. 16, n. 2, p. 217-227.

QUADROS, R. M. de; CRUZ, C. R. Língua de sinais: instrumentos de avaliação. 1. ed. Porto Alegre: Artmed, 2011.

QUADROS, R. M. de; SCHMIEDT, M. L. P. Ideias para ensinar português para alunos surdos. Brasília: MEC, SEESP, 2006.

QUIXABA, M. N. O.; JUNIOR, J. B. B. Aplicativo LibrasApp: Uma proposta para ampliar o ensino e aprendizagem de Libras. Temática, 2016. v. 12, n. 5.

REIS, S. C.; GOMES, A. Podcasts para o ensino de Língua Inglesa: análise e prática de letramento digital. Calidoscópio, v. 12, n. 3, 2014. p. 367-379.

ROGERS, Y.; SHARP, H.; PREECE, J. Design de interação: além da interação humano-computador. 3. ed. Porto Alegre: Bookman Companhia Ed, 2013.

SKLIAR, C. Atualidade da educação bilíngue para surdos - processos e projetos pedagógicos. 4. ed. Porto Alegre: Editora Mediação, 2013. 